\title{
DIDÁCTICA Y CURRÍCULO PARA EL DESARROLLO PROFESIONAL DOCENTE
}

\author{
Navarro, R. (coord.) \\ Dykinson, Madrid, 2011, 318 págs.
}

En el área de educación, la didáctica y el currículo son temas fundamentales y recurrentes cuando de formación profesional se trata. La didáctica como la ciencia que optimiza los procesos de enseñanza aprendizaje; el currículo, como una disciplina de la primera, orientada al desarrollo de planes y programas de estudio.

El libro trata las cuestiones didácticas y curriculares de siempre, puesto que desarrolla los bloques temáticos fundamentales que integran una asignatura de didáctica general. Estas temáticas son: la ubicación de la didáctica dentro del campo de la ciencia; las diferentes concepciones de esta de acuerdo a las teorías didácticas; los enfoques de la investigación didáctica; el proceso de enseñanza aprendizaje como el objeto de estudio; la comunicación, sin la cual la enseñanza no puede promover el aprendizaje; además del currículo y sus elementos esenciales.

Este no es un libro que recopile simplemente los grandes temas de la didáctica; sin embargo, su presentación y tratamiento resultan 
de interés para los estudiosos de esta área de conocimiento, los profesionales de la educación y los profesores en particular. La obra recoge la vasta experiencia profesional de las autoras dentro de la formación de maestros y licenciados en pedagogía, mediante la enseñanza de la asignatura de didáctica general; el texto refleja no solo sus conocimientos, sino además su experiencia docente y de investigación.

Además de lo anterior - ya de por sí valioso— se aborda el tema de la didáctica y del currículo, atendiendo a temas emergentes de la investigación educativa, como la formación de profesores con las competencias necesarias para ayudar a los estudiantes a educarse en un contexto que demanda aprender a reflexionar de manera científica, para pensar y participar en el mundo contemporáneo.

El libro da prioridad al aprendizaje sobre la enseñanza lo cual, en primera instancia, no resulta novedoso: ha sido una lucha que las metodologías activas propugnan desde principios del siglo XX; sin embargo, aquí se acentúa que la formación didáctica ha de llevar a ser expertos en la enseñanza, es decir, a aprender a enseñar, lo cual revitaliza la importancia del papel del profesor con la convicción de que la calidad de la enseñanza depende, en gran medida, de la talla personal, científica y pedagógica de los hombres y mujeres dedicados a la docencia.

El protagonismo del profesor como impulsor del aprendizaje atiende a la necesidad de formar estudiantes para una sociedad cambiante, compleja y en continua transición. La educación, como impulsora en la solución de problemas sociales, no alcanzará su objetivo mientras se deje solos a los profesores y el resto de la sociedad se inhiba de sus responsabilidades educativas. Lo anterior muestra un punto fundamental para el desarrollo: por un lado, de investigaciones en el campo educativo y, por el otro, de proyectos didácticos y curriculares de educación informal.

El libro consta de diez capítulos. Los cuatro primeros, escritos por Rosario Navarro, coordinadora de la publicación, se dedican a la dimensión teórica de la didáctica; a partir del capítulo V, el tema central es el currículo como campo de estudio y aplicación de la didáctica. 
Capítulo I. «Conceptualización de la didáctica».- La autora expone, atinadamente, aspectos relevantes y necesarios para comprender este campo del saber, a partir de un análisis epistemológico de la ciencia y sus principales características. Otro aspecto de interés es el análisis sobre la investigación didáctica que presenta una síntesis de los principales paradigmas y enfoques para la investigación del proceso didáctico.

Capítulo II. «La enseñanza como concepto básico de la didáctica».- El aprendizaje sobre la enseñanza es el punto medular de la reflexión en este campo del saber; ello no implica que el aprendizaje deje de ser importante, sino que será optimizado en tanto que el profesor sea un experto para dirigirlo. Lo anterior enfatiza la función docente y la enaltece. En el capítulo se retoman las principales perspectivas, teorías y modelos de enseñanza.

Capítulo III. "El aprendizaje como medio de formación educativa».Se retoman las teorías, formas y los enfoques del aprendizaje, vinculándolos a la enseñanza, aspectos fundamentales para una mejor comprensión del saber didáctico.

Capítulo IV. «La comunicación didáctica y el clima de aula».- La autora enfatiza la estructura sistémica del proceso de comunicación en los espacios áulicos, además de valorar positivamente los factores y las características de un aula personalizada para consolidar un clima promotor del aprendizaje.

Capítulo V. «El currículo como campo de estudio y aplicación de la didáctica».- Las autoras, Manuela Barcia y María Asunción Bravo presentan, sintética y estructuradamente, las funciones, teorías, los tipos y niveles del diseño curricular, lo que promueve una mejor comprensión de este ámbito y una orientación específica para los profesores que están inmersos en el desarrollo de planes y programas de estudio.

Capitulo VI. "Programación y elaboración de unidades didácticas».- Escrito por Manuela Barcia y Margarita Rodríguez, se centra en la teoría y práctica de la planeación didáctica mostrando ejemplos de programaciones elaboradas por profesores de 
educación infantil y primaria. Lo anterior, resulta muy esclarecedor para quien se encuentra en período de aprendizaje de procesos curriculares. De especial interés es la explicación sobre las formas de organización de contenidos, pues queda clara la diferencia entre la planeación curricular multidisciplinaria, interdisciplinaria, transdisciplinaria y metadisciplinaria.

Capítulos VII, VIII y IX.- Los escriben Margarita Rodríguez, Manuela Barcia y Soledad García. Reflexionan, de manera práctica, sobre los temas de las estrategias, los medios y recursos didácticos, y la evaluación respectivamente. Ello permite una valiosa orientación para su adecuada selección, durante la planeación de procesos de enseñanza aprendizaje, en educación infantil y primaria.

Capítulo $X$. «Funciones y competencias del profesorado».- En este último capítulo, Rosario Navarro y María del Carmen Corujo, analizan la identidad profesional del docente y dilucidan las cualidades que requiere para enfrentarse a los retos que la formación de estudiantes demanda.

Finalmente, podemos concluir que la exhaustividad y claridad en el manejo del contenido sobre el saber didáctico, posiciona al libro como un referente fundamental tanto para los profesores universitarios, que imparten asignaturas de didáctica, como para los estudiantes en formación y los docentes de cualquier nivel educativo. 